\title{
Gestión de los contenidos documentales en el ámbito de la publicidad y las relaciones públicas
}

\author{
Juan Carlos Marcos Recio \\ Juan Miguel Sánchez Vigil \\ Belén Fernández Fuentes \\ Universidad Complutense de Madrid (España)
}

\section{Resumen}

Se analizan los sistemas de gestión documental que ofrecen algunas agencias de publicidad y cómo resuelven las carencias informativas aquellas que carecen de centro de documentación. Se ofrecen algunas fuentes de información empleadas en la creación publicitaria. Se muestra la realidad actual de la documentación en el área de la publicidad y se proponen opciones para mejorar las técnicas documentales que se deben usar en las campañas publicitarias, como es el trabajo del planner o los datos facilitados por los gabinetes de relaciones públicas. Se concluye que la labor del documentalista es recoger, organizar y proporcionar información sobre el producto, la competencia y el consumidor para cada proyecto.

Palabras clave: Publicidad. Gestión de la información. Fuentes publicitarias. Centros de documentación. Función del planner. Investigación.

\section{Abstract}

The documentary management systems offered by the advertising agencies are analysed, together with the way in which the lack of information is resolved by those who do not have their own documentation centre. A series of information sources used in the creation of advertising is provided. The current reality of documentation in the advertising sector is covered and options are proposed for improving the documentary techniques which should be used in advertising campaigns, such as the planning tools or the data furnished by the public relations departments. It is concluded that the role of the information and documentation professional is to collect, organize and provide information on the product, the competition and the consumer of each project.

Keywords: Advertising. Handling of information. Advertising sources. Documentation centres. Planning functions. Research.

Scire. $11: 2$ (sep.-dic. 2005) 79-98. ISSN 1135-3761. 


\section{Introducción}

La publicidad es uno de los sectores con mayor empuje y desarrollo económico en España. En algunos países se convierte además en un referente que ayuda a fomentar la estabilidad social y en consecuencia a mejorar la relación económica de las empresas con los consumidores. Sin una in/formación, entendiendo la palabra en el doble sentido, el usuario tendría que hacer un esfuerzo suplementario para conocer los productos y las ventajas que ofrecen unos frente a otros. Porque la publicidad es, sobre todo, información, ya que facilita al consumidor las ventajas de un producto, datos sobre el precio, lugar de producción e incluso las carencias que puede tener quien no utiliza ese producto. Pero, al mismo tiempo, la publicidad cumple una función social ya que con su mensaje está formando a la sociedad. Con razón aseguran los expertos en publicidad que el fin último es la venta del producto para que la empresa consiga excelentes ingresos, que a su vez posibiliten el pago del trabajo publicitario. Nadie cuestiona esa realidad porque a fin de cuentas la actividad publicitaria no es más que un proceso económico en el que una empresa, una institución, un grupo, una persona o un colectivo quieren vender un producto, una marca o una idea. Sin embargo, no está reñida esa función con la de hacer una sociedad más justa y mejor formada.

"Las autoridades avisan de que fumar puede provocar cáncer" o "Lea atentamente las instrucciones de este medicamento y consulte a su farmacéutico" suenan una y otra vez en la radio y la televisión para orientar al consumidor sobre los posibles daños o beneficios cuando se quiere poner en práctica el mensaje de ese anuncio. No sería justo olvidar que el mensaje principal, tanto gráfico como textual o visual, lo ocupa el nombre o marca del producto, y que primero la publicidad ha conseguido que la atención se fije en él y luego, en una esquina del paquete de cigarrillos o en escasos segundos del mensaje publicitario audiovisual, figura el mensaje social.

Se ofrecen también algunos datos sobre la inversión en España para determinar la importancia de este sector. Para ello, es necesario acudir a una de las empresas que mejores investigaciones hacen en este sentido: InfoAdex. Los datos facilitados en su último "Estudio de InfoAdex de la inversión publicitaria en España 2004" indican que la inversión publicitaria en 2003 alcanzó los 12 015,3 millones de euros, es decir, un crecimiento del 2,6\% sobre los 11 714,2 millones del año anterior. El reflejo de esas inversiones en los diferentes medios quedó configurado de esta forma: 5570,9 millones de euros a los medios convencionales (TV, diarios, revistas, suplementos y dominicales, radio, cine, exterior e Internet), lo que supone el 46,37\% del total; 6444,4 millones invertidos en los soportes no convencionales, que suponen el 53,63\% restante. Estos últimos medios tuvieron en su conjunto un crecimiento del $3 \%$ sobre 2002, mientras los no convencionales (mailing, buzoneo y folletos, rótulos, anuarios, patrocinios y otros) aumentaron un 2,2\%, siempre res- 
pecto al año anterior. Por lo que respecta al PIB, la mayor parte lo aporta el sector servicios, es decir, las comunicaciones, el turismo, la automoción y la publicidad. El volumen de negocio publicitario, según datos de InfoAdex, es del 1,64 del PIB, lo que representa una cifra importante dentro las actividades empresariales.

\section{Documentación y publicidad: concepto de documentación publicitaria}

Las relaciones entre la documentación y la publicidad no son muy estables. Con frecuencia, el trabajo publicitario obedece a un acto de creatividad, dentro de un proceso final de comunicación en el que se crea un mensaje con alto contenido comercial. La publicidad, dicen los profesionales, informa, seduce levemente y tiene que inducir a la compra. Nada se habrá ganado haciendo una campaña maravillosa, recordada por mucha gente, si al final no se vende el producto. El cliente habrá perdido cuota de mercado, su competencia se habrá asentado en el mismo e incluso no podrá seguir invirtiendo en publicidad si los resultados han sido muy desfavorables. Hay un punto de partida común. Ambas ciencias están enclavas en procesos de comunicación en los que la información es el elemento básico. El resultado final en la publicidad es una campaña, un anuncio, un comercial, y siempre transmite un mensaje. En el trabajo documental se genera un documento que también ofrece una o varias informaciones sobre un hecho o acontecimiento.

Por tanto, la documentación y la publicidad son dos caras de una misma moneda, inseparables y complementarias. Quizás, donde radica la separación es en la denominación. La mayoría de las agencias cuentan con un servicio de investigación, también llamado de planificación, que se encarga de realizar las tareas documentales. Todo acto creativo necesita una información previa. La magia, la chispa, la leve sonrisa que conquistará a un gran grupo de consumidores, el toque sutil, la ingenuidad, la sencillez elevada al mundo del arte, etcétera, no irrumpen en la mente del creativo si este antes no ha creado en su interior una gran acervo cultural. Oír, ver y actuar debería ser el lema de algunos publicitarios. Hay que escuchar a la gente, y de esa forma el lenguaje le será más próximo cuando esté creando el texto; ver muchos anuncios, ver todos los anuncios: texto, gráfica, audiovisuales e incluso los que se emiten en Internet. Además de todos esos procesos, el flujo informativo que cada día se crea en los anuncios que se emiten ha de ser otra de las referencias válidas para saber cómo enfocar y plantear algunas ideas. Este proceso se rompe cuando el creativo, sin un gran esfuerzo, ha encontrado la idea sublime, la gran ola que buscan los "surfistas". Pero, hasta que no se prueba y se experimenta, el resultado sigue siendo incierto. De ejemplos de grandes ideas que se convirtieron en pésimas campañas están llenas muchas agencias. Y al contrario, salir con ciertas dudas y terminar por ser una gran campaña, no solo por los premios

Scire. 11 : 2 (sep.-dic. 2005) 79-98. ISSN 1135-3761. 
recibidos, sino por la satisfacción del cliente en su cuenta de resultados es otra forma de hacer el trabajo publicitario, si bien no se puede dejar nada al azar.

Es necesario, antes de seguir, precisar el concepto de publicidad y el de documentación. Así, la American Marketing Association (1999) dice que "la publicidad es cualquier forma de presentación de los hechos sobre mercancías, servicios o ideas, dirigidos a un grupo determinado"; la Gran Enciclopedia Rialp (1979) afirma que Publicidad "es comunicación en masas, pagada, que tiene como propósito último transmitir información, crear una actitud o inducir a una acción beneficiosa para el anunciante", y por último Sánchez Guzmán (1979) señala que "la publicidad puede beneficiarse de una sistematización de los conocimientos que han ido configurándola como técnica de ventas primero y como forma de comunicación específica, después".

$\mathrm{Al}$ analizar cualquiera de las definiciones sobre publicidad, la mayoría de ellas incluyen la palabra comunicación: información, datos sobre una idea producto o servicio. Por tanto, hay dos aspectos destacables en estas definiciones: por un lado, la comunicación del producto, la información específica acerca de sus ventajas, el mercado, la competencia, etcétera, y, por otro, el ámbito comercial, que incluye un pago por los servicios que en este caso facilita la agencia a través de su trabajo. Se puede ver la publicidad como un periódico que informa sobre productos. Y quien paga por esa información tiene más ventajas porque está mejor informado. Si esta aplicación se hace dentro de Internet, las ventajas aún son mayores, puesto que gran parte de la publicidad es gratis en la Red, de tal forma que ya no se necesita una inversión inicial, y además se muestran las mejores opciones de compra, lo que permite al usuario un ahorro considerable. El ejemplo más claro sería la compra de billetes de avión y viajes de vacaciones. Internet contiene publicidad de viajes y los consumidores desean recibir ese tipo de publicidad porque un día o unas horas antes pueden conseguir un billete por la mitad o menos de su precio de salida. ¿Quién no estaría dispuesto a recibir esa publicidad (información) tan beneficiosa para su economía?

Por su parte, la documentación recoge todos las funciones del proceso informativo. No hay que olvidar que el producto final es un documento que muestra aspectos informativos varios con un destino final para los usuarios. De ahí la tarea importante que tiene la documentación como elemento de conservación y utilización de las informaciones, lo que en la actualidad se conoce como gestión de la información, sobre todo en los ámbitos profesionales. Dicen los profesores López y Ros (1993) que la documentación

puede entenderse como conjunto de las disciplinas (ciencias de la documentación) relacionadas con el estudio del documento como fuente de información para obtener nueva información o una toma de decisiones, disciplinas..., o si se prefiere, el estudio de los procedimientos netamente informativos subsiguientes al tratamiento técnico de los documentos para la eficaz difusión de los mensajes en ellos contenidos.

Scire. 11 : 2 (sep.-dic. 2005) 79-98. ISSN 1135-3761. 
En efecto, lo que hace eficaz a la documentación es aportar nuevas fuentes de información que a su vez sirven para la toma de decisiones. En el desarrollo de una actividad o campaña publicitaria cada una de esas fuentes ha de orientar al creativo en su trabajo, ha de constatar que los medios ofrecen un número determinado de audiencia y ha de servir también para conocer datos socioeconómicos sobre el producto y las necesidades de los consumidores. Pero la documentación es más amplia y ofrece muchas formas de actuación porque los recursos con los que trabaja son múltiples y cada día aparecen nuevos soportes que recogen la información. Así, el profesor Izquierdo (1995) se apoya en estos soportes para definirla: "por documentación es preciso entender los medios propios para transmitir, comunicar y propagar informaciones y los datos científicos (libros, periódicos, circulares, catálogos, etc.); en una palabra, los documentos que sirven para realizarla".

Si se aproximan estas dos ciencias, los resultados servirán para que la publicidad tenga a su disposición abundante información para su trabajo, y la documentación, diversos materiales para ofrecer luego como elementos informativos. No pueden, en ningún caso, estar separadas, pues ambas tienen como materia prima la información, y sin ella sus logros serían escasos. Además, la información está en constante evolución. Los datos facilitados en el último estudio que se empleó para una campaña probablemente no sirvan para la siguiente, puesto que habrán variado sustancialmente. Esa es una tarea prioritaria para la documentación, ya que la publicidad demandará datos recientes y actualizados. La comunicación publicitaria se dirige a un sector concreto, tiene su target especifico y para él ha de trabajar el documentalista.

El acercamiento entre estas dos disciplinas se ha realizado a través de algunas publicaciones desde la universidad. Pioneros en este trabajo fueron Martín Martín (en 1987) y José López Yepes (en 1989). Más recientemente acaba de aparecer la obra Gestión de la documentación en la publicidad y en las relaciones públicas, de los también profesores Marcos, García y Nuño (2004). En este libro se recogen por primera vez de forma conjunta ambas actividades, los desarrollos publicitarios, los análisis documentales y las implicaciones entre ambos. En este sentido, estos tres autores definen la documentación publicitaria como "aquella ciencia que ofrece datos contrastados, precisos y complementarios al briefing y que permite desarrollar nuevas ideas para llevar a cabo una campaña publicitaria". Por tanto, la documentación se convierte en un puente que da servicio a cada uno de los departamentos de la agencia, especialmente a tres de ellos: creatividad, planificación y cuentas.

\section{Tareas documentales al servicio de la publicidad}

No existen estudios oficiales sobre el número de agencias que tienen centros de documentación. Con ese nombre muy pocas, a tenor de los trabajos realizados Scire. 11 : 2 (sep.-dic. 2005) 79-98. ISSN 1135-3761. 
por los alumnos de la especialidad que han de analizar y evaluar estos centros. A lo largo de casi una década de docencia en publicidad y relaciones públicas se ha constatado que las agencias realizan funciones documentales, pero no con esa denominación. Utilizan otras, como puede ser departamento de investigación, investigación o planificación. En todo caso, la mayoría de ellas llevan a cabo acciones complementarías a la propuesta que les hace el cliente. Esas tareas, independientemente del nombre que reciban, emplean técnicas documentales para conseguir la información que necesitan, estudios de mercado para determinar los gustos y las necesidades de los consumidores o un seguimiento a las audiencias para saber dónde y cuándo se ha de mostrar el anuncio. Son actividades que requieren unas técnicas concretas. Aunque la persona que las ejecuta no sea un documentalista tendrá que seleccionar la información, analizar cuál es la más importante y preparar y elaborar resúmenes para que en poco tiempo cualquier publicitario acceda a esa información.

\subsection{La importancia de los centros de documentación}

La publicidad es una estrategia de comunicación que actúa en escasos segundos. A lo largo de muchas décadas, el mensaje comercial impreso se conservaba incluso más tiempo que algunos productos. Luego, cuando el consumidor entró en la radio, tuvo que activar su atención de manera inmediata, separando incluso el mensaje nuevo del que acababa de escuchar. En la televisión el tiempo también es reducido, pero se juega con la magia de la imagen. También aquí casi siempre el consumidor ha de seleccionar de un grupo de anuncios uno o dos, los que más le interesen; o ninguno, ante la insistencia de mostrar bloques tan extensos que hacen que se pierda un gran porcentaje comunicacional. En Internet cambian un poco las estrategias porque el cliente puede obtener más información en el acto. La tendencia de la publicidad pasa por aprovechar estos recursos interactivos, de tal forma que ya se hacen campañas conjuntas entre televisión e Internet. Así, se muestra un mensaje comercial en la televisión y se pide a los usuarios que voten un aspecto de esa campaña a cambio de recibir un premio o participar en un sorteo. La otra opción, ya planteada por Damm, permitía a los consumidores determinar cómo tendría que acabar la campaña, porque en la publicidad emitida por la televisión quedaba inconclusa.

Ante este panorama en los medios, el publicitario hace un esfuerzo por estar in-formado, es decir, por actualizar cada día su bagaje cultural. Accede a los medios de comunicación, acude a reuniones con su cliente, que le va informando sobre las ventajas del producto, escucha mensajes comerciales de otros colegas, mira la televisión de manera crítica para aprender, busca en el cine nuevos recursos, navega por Internet para que gente que no es experta le ofrezca visiones y situaciones nuevas. Y todo ello para que su espíritu creativo esté siempre en ebullición. De esa manera será más fácil que el proceso comunicativo sea eficaz.

Scire. 11 : 2 (sep.-dic. 2005) 79-98. ISSN 1135-3761. 
¿Cómo contribuye la documentación a la formación de cada uno de los publicitarios? Si bien los estudios realizados por los publicitarios son diferentes, siendo su origen diverso, desde economistas hasta historiadores, sociólogos, etcétera, en el ámbito de trabajo de una agencia se suman esas diversidades, esas funciones contradictorias para hallar una idea genial. A ese esfuerzo colectivo ha de colaborar, como si fuera un ente más, la documentación. Cierto es que no existen como tales muchos centros en las agencias, pero ya se ha constatado en este trabajo que la publicidad es sobre todo información, y quien más y mejor está acostumbrado a usarla es el documentalista.

La creación de centros de documentación es reciente, apenas tiene dos décadas. El punto de partida es diferente en función de la propiedad de la agencia. Hay que indicar que muchas de las agencias españolas están agrupadas o pertenecen a alguna multinacional. En este caso, la importancia de tener un centro de documentación es menor, ya que las informaciones se obtienen de la agencia más importante del grupo. En aquellas de menor producción publicitaria, el esfuerzo y las inversiones han sido mayores, quizás por la carencia de ayuda desde otras agencias. En España, Clarín, J. Walter Thompson, Tiempo BBDO y Grey han apostado por un lugar físico para guardar y clasificar los documentos que se generan dentro de la campañas que realizan (1).

Dentro de este grupo se podrían añadir algunas agencias más, pero esa gran mayoría que realiza acciones documentales no lleva a cabo todo el proceso. De hecho, muchas de ellas disponen de un espacio físico que llaman biblioteca y en el que se guardan sin ningún tipo de orden algunos libros sobre creatividad publicitaria, algunas revistas de arte y anuncios gráficos de su propia producción. Como no existe una cultura de conservar los documentos, la mayoría de los estudios que se encargan para una campaña terminan por desaparecer. Cierto es que el mercado cambia constantemente y que quizás no sirvan para una nueva que llegue dentro de dos meses, aunque en ocasiones análisis e investigaciones de carácter general sí son válidas, pero hay que volver a realizarlas porque no se conservan los resultados. Visto de esta manera, en una gran parte de las agencias se debería hablar más de biblioteca que de centro de gestión documental.

Una de las agencias pioneras en España en el tratamiento documental fue Clarín. Más recientemente, Tiempo BBDO constituyó un centro de documentación para dar servicio a las agencias que forman el grupo. En su sede de Barcelona, los documentalistas son conscientes de que la publicidad cambia constantemente, el mercado no permanece estático y la sociedad que recibe el trabajo publicitario evoluciona con rapidez. De esta forma, han de buscar nuevos datos en todos esos sectores: cliente, producto y consumidores. La responsable del centro, Rosa Lussá, valora de forma muy positiva esa información que complementa el trabajo publicitario, sobre todo porque en las agencias se apuesta por otras funciones, como

Scire. 11 : 2 (sep.-dic. 2005) 79-98. ISSN 1135-3761. 
asesorar a los clientes y dar servicios de información: "Parece que la tendencia de las agencias de publicidad es llegar a convertirse en consultoras de comunicación y eso significa poder aconsejar al cliente cuál es la mejor opción de comunicación en cada momento" (Marcos, 2004). La función de búsqueda se hace aquí prioritaria, mientras que en los centros de documentación convencionales es el análisis el que predomina. Esta función es una aportación de la documentación publicitaria.

En el centro de documentación de Tiempo BBDO se ejecutan la mayoría de las tareas, entre ellas la selección y el proceso de búsqueda de información para los clientes habituales, pero también de aquella que es interesante y que pueda servir en un futuro. El principal problema de este y otros centros es el cambio de clientes. Si un cliente, de repente, decide contratar otra agencia, el centro se queda huérfano. No sabe si ha de seguir recogiendo información por si algún día regresa o, cuando lo haga, recuperar todos los documentos actuales que ese cliente demanda ahora. Sin embargo, muchas veces situaciones de marketing o de creatividad se resuelven sobre la marcha. Ahí es donde el centro tiene que demostrar su efectividad, pues ante una situación de cambio en el trabajo publicitario pueden aparecer nuevas líneas propuestas por el cliente o fruto de la creatividad y, como requieren de nuevos datos e informaciones, el documentalista ha de actuar en consecuencia, con rapidez y ofreciendo varias opciones informativas, si bien el proceso documental se puede resumir en una acción con dos frentes: conocer el mercado y el público al que se dirige la campaña y obtener los datos de ambos para que se empleen en creatividad, planificación y marketing.

Otra de las agencias que ha dispuesto de servicio documental es McCann Erikson, aunque algunas de las funciones documentales se han paralizado. Durante varios años el centro tenía un "director de información" que se ocupaba del proceso informativo dentro de la agencia. Estaba directamente vinculado con el departamento de cuentas, mientras que en otras agencias depende del de planificación. Así pues, no se valora como departamento separado y sus funciones dependen del área al que esté asignado. Las actuaciones principales realizadas por el director de información tenían como finalidad la consecución de informaciones sobre el producto, además de las que facilita el cliente, el mercado, la competencia y sus movimientos, sus acciones inmediatas y su reacción ante la llegada de un producto similar, búsqueda sobre el precio, sobre todo el que muestra la competencia y, en general, ampliación de aspectos colaterales de cada una de estas situaciones previas que se producen en el momento de preparar una estrategia de comunicación publicitaria.

Por su parte, en Grey España también se apuesta por la documentación. Tradicionalmente ha existido un centro, conocido como DataMedia, que ofrece información a las agencias de Madrid y Barcelona y que durante algún tiempo además comercializaba su propia producción. En esta agencia se proyectaba más el 
análisis documental que la búsqueda de información. Para ello, trabajaban con imágenes, es decir, transformaban el soporte de la cinta de vídeo a fotocopy o telecopy para valorar anuncio por fotograma, e incluir luego en cada fotograma los rótulos que le correspondieran. Se constata así un seguimiento de la imagen y además se añaden recursos textuales que van desde un simple descriptor hasta un resumen de contenido de los principales anuncios.

El resto de las agencias no aplican el proceso documental, pero a grandes rasgos se preocupan por conseguir datos que el cliente no ha facilitado, que no tiene, que están mal enfocados, etcétera. Es un labor que exige el manejo de fuentes de información, no solo las estrictamente publicitarias, sino las que presentan datos sobre el mercado y el consumidor, los dos frentes que han de conocer a la perfección todos los implicados en una campaña. Por tanto, la carencia de centro como tal no impide que exista una persona, planner, documentalista, gestor, etcétera, que realice las tareas informativas para cada uno de los departamentos de la agencia.

\subsection{Algunas fuentes para la publicidad}

La creación de anuncios publicitarios tiene como fin convencer al consumidor de que compre un determinado producto. Para ello, ha de presentarse de forma que cuando perciba el mensaje se guarde en su memoria e inmediatamente acceda a su compra. Así, la publicidad actúa para todos los consumidores y utiliza todos los recursos informativos a su alcance. Bien es cierto que algunos se emplean más que otros. En este sentido, se recogen varias fuentes que en la mayoría de las agencias se emplean como punto de partida.

1. Internet. Es la principal referencia del trabajo documental de las agencias. $\mathrm{Al}$ no disponer de centro de documentación acuden a consultar fuentes institucionales que garantizan al menos que los datos son verdaderos. La ventaja para los publicitarios es que ahí dentro encuentran casi todo, pero la contrapartida es la gran cantidad de tiempo que invierten.

2. Bases de datos. Ofrecen referencias concretas y puntuales sobre el mercado, el producto y el consumidor de manera estructurada, lo que permite una rápida recuperación y uso. Sin embargo, no existen muchas bases de datos específicas o dedicadas en general a la publicidad; más bien ofrecen datos sobre productos y audiencias de los medios de comunicación para hacer la planificación.

3. Servicios externos. Se trata de una fuente importante, pero quizás demasiado cara. La agencia que carece de centro decide encargar parte de su trabajo de búsqueda de información a centros y empresas que comercializan contenidos. Un ejemplo sería la empresa Teleteca, que se encarga de analizar los anuncios que salen en prensa, radio y televisión; luego hace una ficha documental de cada uno de ellos para su recuperación y los comercializa entre

Scire. $11: 2$ (sep.-dic. 2005) 79-98. ISSN 1135-3761. 
las propias agencias. Es posible que una agencia prepare una nueva campaña para un modelo de coche y quiera visualizar todos los anuncios de esa marca en los últimos cinco años, o todos los anuncios de ese segmento de coches en el mismo periodo. En este sentido, la empresa Teleteca se convierte en una fuente para aquellas agencias que carecen de centro. A nivel internacional existen otras empresas que facilitan recursos informativos; entre ellas, las más consultadas por las agencias españolas son Xtreme Information, The Register y Data Monitor. Estas ofrecen además estudios de campo, tests, encuestas de todo tipo sobre el producto y los consumidores. Lo normal es hacer un contrato de servicios entre la agencia y la empresa que comercializa la información, pero también se pueden demandar servicios concretos para una determinada campaña. Las principales empresas que hacen este tipo de estudio, tan necesario como efectivo en la publicidad, son Cibernos, Andersen, Gallup España y Taylor Nelson Sofres.

4. Periódicos y revistas. Se han convertido en una referencia informativa dentro de las agencias. Quizás los de información general solo aportan ideas, datos, informaciones sobre qué piensa y cómo actúa la sociedad, pues los medios reflejan sus actividades. Sin embargo, para conocer el trabajo publicitario de otras agencias, existen revistas especializadas en el sector como Anuncios, IPMark, Control o las que se encuentran en Internet y muestran abundantes campañas publicitarias (Adlatina o Mercadeo y Publicidad, entre otras). Por supuesto, revistas y medios que trabajan con estudios sociales, datos de mercado y estrategias de los medios han de ser conocidas por los publicitarios y se convierten en una fuente obligatoria para conocer mejor al consumidor. Los publicitarios aseguran con frecuencia que nunca se sabe todo del consumidor. Cierto es, porque los estudios indican una tendencia y la realidad luego va por otro camino.

5. Centros de la imagen: agencias fotográficas, empresas y organismos que tratan y analizan la imagen, ya que esta es un referente constante en la publicidad. La mayoría de las campañas incluyen elementos fotográficos. Unas veces como complemento del texto, para reforzar la idea principal; otras, son el núcleo principal de la campaña, ya que su posición y su mensaje recogen la idea esencial que se transmite en ese mensaje. En ocasiones, no hace falta consultar estas bases de datos o los fondos que tienen las instituciones, pues la fotografía no existe y hay que realizarla para esa campaña. Para el resto, existen en España empresas como Age Fotostock, Index Fototeca o Stock Fotos, entre otras, que tienen a la mayor parte de las agencias en su nómina. Son lugares donde se guardan, seleccionadas y clasificadas con sus descriptores para hacer una búsqueda rápida, millones de fotos de los más variados temas, e incluso con resúmenes de contenido. A 
veces no se emplean como estrategia directa, pero ayudan a los creativos a tomar decisiones; por eso se hace necesario visualizar aquellas imágenes que son significativas y que pueden arrancar un sentimiento, una emoción o una reflexión al usuario cuando las vea. Es el primer paso para que la vista del consumidor se detenga unos minutos al lado de la marca comercial que se instala a su lado. El trabajo de selección y luego su ubicación han de hacerse con mucha sensibilidad y conjugando bien la imagen o imágenes con los textos que se han preparado. En caso contrario, la atención derivará hacia otro lado y se habrá perdido un futuro consumidor.

6. Fuentes oficiales. Ofrecen multitud de informaciones y estudios realizados por la Administración, algunos de ellos de importancia capital para la publicidad, como pueden ser los datos sobre la población del Instituto Nacional de Estadística. Pero también se recogen experiencias, análisis y dosieres sobre gustos, necesidades e intereses de algunas comunidades. No hay que olvidarse tampoco de estudios similares realizados en el ámbito privado pero con un interés público, como pueden ser algunos excelentes trabajos publicados por fundaciones o institutos sociales y que a veces no están al alcance de los publicitarios por desconocimiento.

La última fuente con la que se cuenta son los propios estudios y tests que se hacen con una serie de consumidores. Se trata de una fuente directa, un análisis en el que se toman las referencias de manera presencial y los datos que se obtienen se trasvasan al resto de la población. Los resultados son considerados trascendentales porque de esas reuniones se obtienen elementos que difícilmente se encontrarían en cualquier otro centro de información. Por tanto, aproximan al creativo hacia una necesidad que se ha detectado como significativa y que sería bien acogida por escasa o por novedosa frente a productos que ya han rebasado los gustos de los consumidores.

Por supuesto, las fuentes clásicas de información también son tenidas en cuenta. Aquí se incluyen al final porque su uso es escaso, y los valores que aportan, menores. Se trata de emplear diccionarios, enciclopedias, atlas, manuales, etcétera, pero o no existen o están sin actualizar; de ahí que no se consideren importantes y que apenas se consulten. Esta carencia viene determinada por la inexistencia de un centro o lugar donde reunir este tipo de fuentes. Si se creara y se mantuviera actualizado, la mayoría de los publicitarios lo tomarían como referencia, conscientes de que a veces ciertos datos que no se consideran significativos son los que resuelven una campaña.

\section{Aportaciones del planner/investigador al proceso informativo}

La primera función que ha de cumplir el planner es la de completar los datos recibidos del cliente, comprobar su veracidad, conseguir sus ventajas, sus puntos Scire. 11 : 2 (sep.-dic. 2005) 79-98. ISSN 1135-3761. 
fuertes y débiles, y conocer todos los detalles, aunque parezcan poco importantes, del producto. Luego está su competencia: otros productos iguales o similares que tienen un precio determinado, que están posicionados en un determinado lugar del mercado, que utilizan campañas que ya han entrado en la mente del consumidor, etcétera. Cuantos más datos se consigan ahora, más fácil resultará el siguiente paso. Este trabajo suele durar entre dos y tres semanas, siempre que no se exceda el tiempo necesario para implementar toda la campaña. La tarea principal de estas investigaciones es desarrollada en algunas agencias dentro del departamento de planificación estratégica, en el que un planner adelanta el trabajo, o también en el departamento de cuentas. Según Alfonso González, planner de la agencia Remo, el planificador estratégico se ha de encargar de buscar la información, analizarla y dársela deglutida a los creativos, si bien ya cuentan con la ventaja de las propuestas informativas del cliente sobre su producto:

De hecho, puede ser un acto de presunción por parte de las agencias decirle a los anunciantes y fabricantes que tú conoces mejor que ellos su mercado. Esto es un tema delicado. Es posible que encuentres clientes que no conocen su producto o no sepan del todo cómo percibe la gente su marca en la calle, pero hay otros clientes que lo saben muy bien, sobre todo porque son dueños de su negocio y saben cómo funciona. (Marcos, 2004, p. 177)

Desde hace unos años, la figura del planner, del investigador, del que adelanta y busca las informaciones se está consolidando con unas funciones determinadas dentro de la agencia, muy similares a las que realizan los documentalistas. Hasta entonces, ese trabajo se realizaba desde diferentes frentes: directores de cuentas, creativos, investigadores y hasta ejecutivos. Este proceso se está asentando ahora en las agencias y las tareas de investigación se encargan al account planner, conocido básicamente como planner, si bien no en todas se defiende este refuerzo informativo, ya que el análisis y la gestión de la información se encargan a empresas externas a la propia agencia. En ocasiones, hasta al propio planner le resulta difícil definir su situación y las fuentes que maneja para su trabajo. Mariana Hernández, que realiza tareas de este tipo en J. Walter Thompson en Madrid, considera que la figura del planner está impulsando los trabajos de investigación en la publicidad:

La llegada de la planificación estratégica y de los planners a la publicidad le ha dado un nuevo significado a la investigación situándola como una fuente de inspiración para entender ciertas pautas de comportamiento y en consecuencia identificar oportunidades de comunicación. (Hernández, 2004)

El trabajo publicitario cambia constantemente; de ahí que una estrategia de varias semanas, de repente, ya no sirva porque el cliente no la ve con fuerza. Las modificaciones constantes de la sociedad, que impone nuevos requisitos para definir los productos y las diferentes realidades en cuanto a gustos de los consumidores, mantienen en acción a los publicitarios. Sin embargo, esta es la situación a la que se enfrenta un documentalista cada día. Su reto principal, como gestor de la in- 
formación, es alcanzar los recursos más actuales, atendiendo a diversos criterios, como el uso del lenguaje, las aportaciones recientes en los análisis y estudios, de tal forma que se puedan aplicar de manera inmediata, y el trabajo retrospectivo en la búsqueda de complementos informativos. En este sentido, las herramientas son similares y las funciones entre el documentalista y el publicitario se aproximan. Lo que cambia es el producto final, en el que el publicitario tiene que crear una campaña, una comunicación sobre un producto o una idea, mientras que el documentalista solo ordena y clasifica los resultados y apenas actúa de forma creativa, excepto cuando confecciona informes o resúmenes documentales en los que aporta datos de su propia formación.

Investigador, documentalista, planner, atención al cliente o comoquiera que se denominen han de tener como prioridad la gestión de las informaciones sobre la propuesta que aporta el cliente, los datos de la competencia, la situación del público objetivo al que se dirige la estrategia de comunicación y los trabajos internos, como la ayuda al departamento de cuentas y, sobre todo, la resolución de las dudas informativas que se le planteen al creativo. En ocasiones, este tiene la campaña estructurada en su cabeza y le falta el empujón definitivo. Un dato, una idea, un informe o un simple apoyo informativo pueden resultar decisivos.

El desarrollo publicitario exige la participación de varios departamentos hasta que llega a la creatividad. Es un ir y venir de un sitio para otro. Un intercambio de ideas para desechar las peores y centrarse en dos o tres que darán forma a la campaña. En ocasiones, ideas calificadas como excelentes encuentran problemas en su realización o en excesivos gastos que el cliente no quiere pagar. De ahí que, una vez clarificada la creatividad, haya que esperar el visto bueno del resto de departamentos para dar validez al trabajo final. Ese desarrollo se refleja de forma notoria en el trabajo del planner que actúa de puente entre los diversos departamentos.

A juicio de Mariana Hernández, estos son los pasos que se emplean en el proceso publicitario, apoyados en el esquema clásicos de comunicación, donde existe un emisor que transmite un mensaje, pero con las limitaciones que impone un mensaje comercial que además de aportar la información ha de actuar como elemento de persuasión para que el cliente opte por la compra:

1. La definición de la estrategia de comunicación: reunir e integrar información que permita establecer el mejor camino para cumplir los objetivos de la marca, es decir, qué tengo que decirle a quién.

2. Durante el proceso creativo: ayudar a inspirar a los creativos con ideas originales y coherentes (todo un reto) y entender cómo funciona la comunicación creada de cara a los consumidores (los temibles pre-tests).

3. La aprobación: brindar al cliente una justificación sólida sobre la estrategia de comunicación y la creatividad.

Scire. 11 : 2 (sep.-dic. 2005) 79-98. ISSN 1135-3761. 
4. Durante el seguimiento: supervisar y participar en aquellas investigaciones que permitan entender y ponderar los resultados de la publicidad (los también temibles post-tests).

Si se analizan estas cuatro funciones de forma comparativa desde el ámbito documental se descubre que la primera de ellas busca la información, selecciona los contenidos para luego facilitárselos a los creativos. Más tarde se incide en el análisis que se hace con los consumidores. Al ser la sociedad tan cambiante, cada campaña, incluso para el mismo producto, requiere nuevos pre-tests; de ahí que el documentalista solo pueda aportar recientes estudios como apoyo complementario. La tercera de las propuestas, si se realiza bien, evita mucho trabajo al resto del equipo. El planner ofrece datos al cliente de tal forma que le resulta más sencillo entender la idea creativa, y hacia dónde y a quién se dirige. Por fin, el cierre del trabajo se determina cuando se obtienen los resultados de los llamados pos-tests, que señalan si el producto ha cumplido las exigencias iniciales impuestas por el cliente y por la estrategia de comunicación publicitaria.

Así pues, el trabajo del planner, lo mismo que el del documentalista, consiste en allanar el camino a los que necesitan información: publicitarios o usuarios. En el primer caso, cuantos más datos se obtengan de los consumidores, que es el objetivo final hacia donde se dirige el mensaje publicitario, mejor. El documentalista, por su parte, ha de conocer lo que demandan con frecuencia sus usuarios para de esta forma dar un servicio activo y de calidad.

Aunque el planner logre los mejores datos y resuelva de forma acertada las peticiones de información que le demandan sus compañeros, siempre dependerá del trabajo del creativo. A veces se presenta una situación favorable porque se tienen todos los datos de cara; sin embargo, el proceso de creatividad se atasca y necesita nuevos elementos para plasmar la comunicación publicitaria. En todo caso, el planner habrá justificado su razón de ser dentro de la agencia. Empieza entonces el turno de los creativos.

\section{Desarrollo de la actividad publicitaria}

El cliente desarrolla una actividad empresarial, fruto de la cual obtiene un producto que ha de vender. Aunque la publicidad siempre ha estado presente, en los comienzos de la civilización esta actividad era escasa. Lo que se producía se consumía en el mismo lugar. Incluso existieron épocas de menor productividad y escasez de recursos. Con la implantación del capitalismo, se crean fábricas y empresas y el ciclo de producción es tan alto que se ha de buscar una salida comercial a la producción sobrante. Ahí empiezan los primeros movimientos serios para convencer a los consumidores de que se acerquen a un producto determinado. Ni siquiera las marcas estaban entonces establecidas. Luego, cuando empezaron a aparecer productos similares, se hizo necesario mostrar las características. El 
publicitario tiene que mostrar las ventajas del producto para el que trabaja y al mismo tiempo ir creando en la mente del consumidor el nombre y el logotipo de esa marca. Más recientemente, esa forma de hacer publicidad ha evolucionado hacia métodos en los que se valora el conocimiento de los consumidores. Mediante estudios se detectan sus necesidades y la publicidad las refleja en sus mensajes. Sin embargo, cuando el producto es bueno ofrece ventajas que ya sirven como esquema publicitario, primero en su creación y luego como nuevos elementos o matices significativos del producto. Recuérdese el "ahora más blanco" o "contiene menos calorías" con que se anuncian los detergentes y las bebidas refrescantes. Por tanto, el consumidor es el referente principal, pero la calidad de ciertos productos actúa como una garantía en la mente de los consumidores.

El proceso de comunicación publicitaria se inicia de varias formas. Una de ellas es a través de concurso. Así, empresas, instituciones y organizaciones ofrecen su cuenta a las agencias de publicidad. En ocasiones, el proceso es cerrado, es decir, no pueden optar más que un número determinado de agencias. Estos sistemas son criticados por los publicitarios, porque a veces realizan mucho esfuerzo y trabajo para no conseguir luego esa cuenta. Sin embargo, son escasas las agencias que renuncian a cantidades tan importantes como las que ofrecen ciertos organismos públicos. La otra forma de conseguir clientes es a través de trabajos ya realizados que han convencido a los futuros inversionistas. Algunas instituciones, por ejemplo la Asociación Mexicana de Agencias de Publicidad (AMAP), ofrecen a los clientes unas indicaciones de qué tienen que hacer para conseguir una agencia, sobre todo las primeras veces que acceden al mercado publicitario. Se dan todas las pautas, tanto las responsabilidades como los derechos, incluido el pago aproximado por los servicios que va a contraer la agencia. Sería necesario precisar el concepto de responsabilidades, ya que cuando un producto no consigue incrementar sus ventas no solo es culpa de la campaña publicitaria; puede haber otros muchos factores, como las características del producto, su sabor, su precio, etcétera. En ocasiones, una vez iniciadas las relaciones, incluso tras unos años de trabajo, la agencia decide prescindir de una cuenta por discrepancias con el cliente o con lo que se dice del producto, pero no suele ser lo normal, ya que conseguir un cliente a veces es cuestión de años, y de los que hacen grandes inversiones en publicidad, mucho más tiempo.

El paso normal es la contratación de los servicios publicitarios por parte del cliente cuando ha conocido de forma directa las explicaciones de los publicitarios. Las primeras reuniones son importantes pero no determinantes. Hay un reconocimiento explícito por parte del cliente que acude a una agencia convencido de que ese equipo puede respaldar su producto como lo ha hecho con otros muchos que ya están compitiendo en el mercado. El cliente no da pasos en falso. Sabe que una parte importante del futuro de su empresa está en manos de los publicitarios. Quiere conocer su trabajo. Ver qué propuestas pueden hacerle. Escuchar opiniones Scire. 11 : 2 (sep.-dic. 2005) 79-98. ISSN 1135-3761. 
sobre otros éxitos y fracasos de la agencia. En todo caso, ambas partes han de dejar clara una cosa. El publicitario crea una comunicación comercial con el fin de que el cliente mejore sus ventas y consiga unos rendimientos financieros complementarios. Puede, pero en ocasiones limitadas, ofrecer propuestas para mejorar el producto, pero eso es una tarea de la empresa. Por tanto, el publicitario ofrece información de las ventajas del consumo del producto para convencer a los consumidores, y el fabricante ha de procurar mejorar y hacer competitivo el producto con respecto a la competencia.

En medio, multitud de posibilidades. Desde productos sin apenas ventajas que gracias a excelentes campañas se convirtieron en los más vendidos de su sector, pasando por mediocres productos y campañas, hasta el fenómeno inverso: excelentes productos ya asentados en el mercado que tras un cambio en la publicidad terminan por bajar en sus ventas de forma considerable. Por último, en este proceso las implicaciones documentales son escasas. Tan solo se puede considerar como trabajo documental la preparación de campañas para mostrar al cliente los últimos trabajos —o los más destacados — con una coherencia que le permita tener una visión global del trabajo de esa agencia.

Cuando el cliente desea aumentar sus ventas, dar a conocer un nuevo producto o recordar a los consumidores que sigue estando en el mercado, acude a una agencia de publicidad. Si es su primera experiencia, se ha fijado en otras campañas de la competencia o en trabajos publicitarios de impacto en otro sector comercial. Cuando llega a un acuerdo con la agencia, se prepara una estrategia en la que participa el departamento de marketing de la compañía, si dispone de él; en caso contrario todo el trabajo lo asume la agencia.

Algunos productos son únicos - los menos — o presentan unas garantías y un precio excepcional para el consumidor. En ese caso, se podría prescindir de la publicidad. Si apenas ofrece nada nuevo o diferencial tendrá que conseguir otros recursos para que el consumidor se acerque a él. Ahí entra en juego la publicidad. El fabricante sabe muchísimo de su producto, porque lo ha creado, y aporta su experiencia en la fabricación; pero el publicitario es el que más sabe de comunicación, de cómo hacer que con un mensaje llegue al consumidor y termine por comprarlo (véase figura 1). Hay que separar de forma clara estas dos funciones. El cliente no puede hacer publicidad, aunque puede apoyar ofreciendo su conocimiento del producto. No debe convertirse en el protagonista. Por contra, el publicitario no ha de actuar como si fuera el fabricante y recomendar algo del producto a partir de la publicidad que se acaba de proponer.

El producto puede ser nuevo en el mercado, llegar por primera vez; por lo tanto, la estrategia de comunicación será diferente que si ya es conocido por los consumidores. Como el desarrollo documental es mayor cuando se trabaja por primera vez en un producto, se parte de este supuesto para mostrar los pasos que se siguen.

Scire. 11 : 2 (sep.-dic. 2005) 79-98. ISSN 1135-3761. 
El cliente ofrece información sobre lo que quiere vender. Se dice con razón que quien mejor conoce su empresa y su producto es el que los piensa, diseña y fábrica, puesto que la publicidad ayudará en la última etapa, es decir, en la comercialización. Para ello se crea el briefing como documento base a partir del cual se empieza a trabajar. Este documento no siempre está presente en el proceso publicitario. A veces es un simple comentario o detalles que aporta el cliente. La agencia recibe la propuesta y se pone en marcha. Son raras las veces que desde el principio se sabe adónde se quiere llegar. En caso contrario se necesitará una o varias investigaciones y búsqueda de información. En esta parte del proceso es donde empieza a trabajar el planner.

La estrategia que se desarrolla en una agencia sigue este esquema:
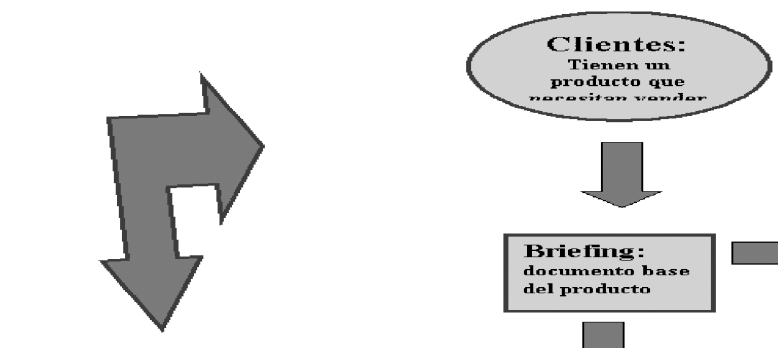

Briefing :

documento base

del producto
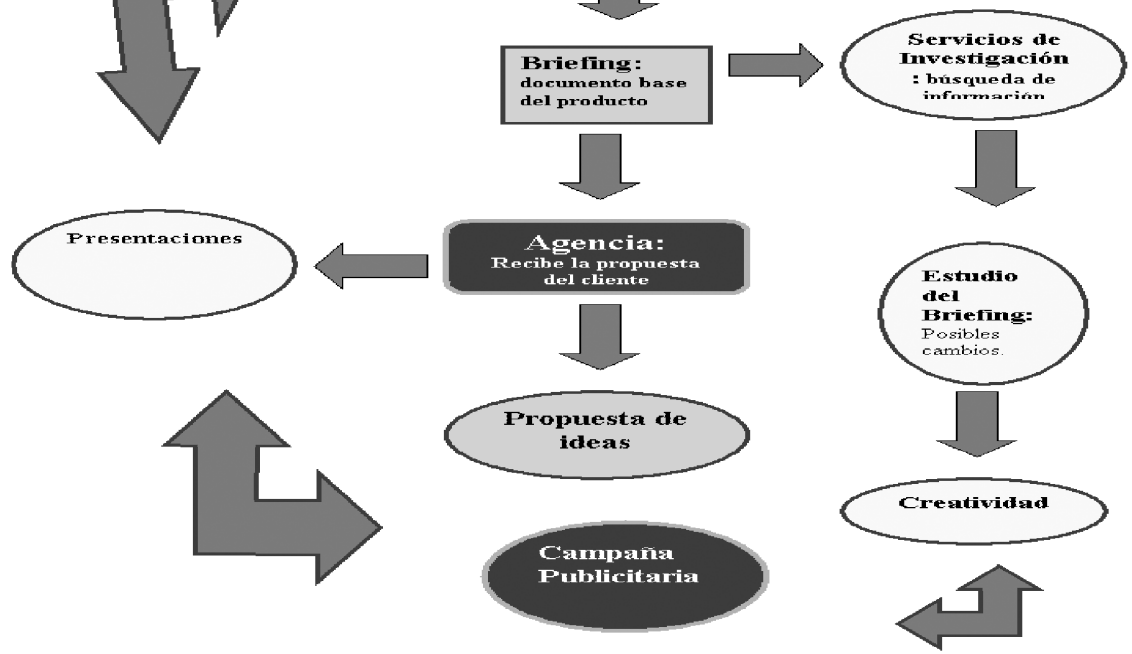

Figura 1. Pasos que sigue un producto hasta que el cliente acepta la campaña.

Puede suceder que, con las informaciones que aporta el planner, el briefing deba cambiarse. En ocasiones se realiza un contrabriefing cuando se producen situaciones que no se ajustan a los datos obtenidos en el mercado. Es necesaria una nueva reunión con los clientes. Puestas de acuerdo ambas partes, se ofrecen los datos e informaciones obtenidos al departamento de creatividad para que empiece

Scire. $11: 2$ (sep.-dic. 2005) 79-98. ISSN 1135-3761. 
su estrategia. Así se llega a la parte más importante de la publicidad. El acto sublime es la creatividad. Todo gira en torno a ella. Y para que ese desarrollo supremo tenga un buen fin, la mayoría de los publicitarios que han cosechado logros en esta fase creativa hablan de trabajo, trabajo y trabajo. Se dice con frecuencia que la publicidad es, sobre todo, creatividad, que el porcentaje más alto es creatividad y que el resto solo ayuda. Quizás sea verdad pero, sin una dedicación constante, sin un esfuerzo cada día, sin una entrega plena en cuerpo y alma a la tarea creativa, el esfuerzo será infructuoso. Uno de los grandes de la publicidad, David Ogilvy (1965), dejó claro hace años dónde radica el buen hacer del publicitario: en la creatividad. "Para tener éxito en Publicidad, hay que contar necesariamente con un grupo de gente creadora. Esto significa tener que tratar con un porcentaje razonablemente elevado de estirados, orgullosos, brillantes y excéntricos inconformistas".

Por su parte, las actividades del documentalista o del planner siguen centradas en suministrar la información a los creativos, pero también empieza a trabajar para otros departamentos, cuentas y planificación de medios, sobre todo. De ahí que en la figura 1 , junto a las respuestas que ofrece el creativo, lleguen otras propuestas e ideas desde el resto de publicitarios de la agencia. De ese conglomerado de propuestas, de esa olla a presión que termina por lanzar un chorro de gas, se obtiene una campaña publicitaria. El paso siguiente es comprobar la realización de la misma. Las agencias tienen contactos con equipos de producción con los que trabajan habitualmente. Si todas las partes aceptan, incluido el departamento de cuentas, se hace la presentación al cliente. Puede ser una única idea muy bien elaborada o varias sobre el mismo tema. Llega el momento cumbre para la creatividad. El cliente dice sí y todo sigue su curso hacia la realización y planificación: pronto veremos un nuevo anuncio. Puede que diga sí, pero con algunos cambios. Es posible que se puedan añadir, o que no. Y puede que no entienda nada y recomiende algo mejor. En ese caso, hay que empezar de nuevo, poniendo en marcha otra vez todos los departamentos para ofrecer un nuevo mensaje comercial que, basado en datos e investigaciones, pueda convencer al cliente y sobre todo a los consumidores para que las ventas se incrementen en función de lo previsto por el anunciante, e incluso se superen estas previsiones.

Una vez que la campaña está funcionando el planner vuelve a entrar en acción. Ha de controlar los estudios y los post-tests que se llevan a cabo. Toda la información resultante ha de circular por los diferentes departamentos de la agencia para que comprueben la eficacia del trabajo o los errores cometidos, porque también de los fracasos se aprende, aunque en publicidad no están permitidos, pues pueden suponer un perjuicio muy grande para una empresa; de ahí que las grandes inversiones se hagan en los procesos iniciales, cuando se ha de conocer todo sobre el consumidor para enfocar hacia él su mensaje publicitario. Si el planner, el documentalista o el gestor utilizan datos e informaciones de calidad, es más difícil que la cam-

Scire. 11 : 2 (sep.-dic. 2005) 79-98. ISSN 1135-3761. 
paña no tenga éxito. Sin embargo, un porcentaje grande de factores influye en el éxito o fracaso de un mensaje comercial.

No hay que olvidar que las relaciones públicas ayudan de forma considerable en la búsqueda del conocimiento humano, algo tan básico pero tan significativo en la creación publicitaria. Las técnicas empleadas en la promoción y servicios que ofrece el producto son otro referente para mejorar la comunicación. Para ello se ha de obtener de la empresa los recursos óptimos que tiene y favorecer con ellos la idea de un producto estable. En este sentido, el proceso informativo es similar al mencionado con anterioridad en la publicidad, de tal forma que las relaciones públicas aportan un análisis del cliente, sus referencias, el sector en el que está enclavado y su competencia. Esos datos forman parte de los que el planner ha facilitado ya en los diferentes departamentos de la agencia.

\section{Conclusiones}

La utilización de la información en una sociedad global no es ajena a la publicidad, que necesita cada día mayores recursos para conocer lo que piensa el consumidor. El mercado ofrece situaciones muy cambiantes, impuestas por un ritmo de vida al que la publicidad da servicio. Por su parte, la documentación ayuda en la gestión ofreciendo los recursos, estudios y análisis que se efectúan en las diferentes áreas temáticas. A veces, los simples datos estadísticos o los informes de expertos sobre lo que piensa un sector de edad determinado son suficientes para orientar una estrategia creativa. La documentación es el refuerzo que apuntala la idea principal que configura al final ese mensaje comercial. Es posible que la función la ejecute un planner, un investigador o un ejecutivo de cuentas, pero a la postre se trata de una actividad documental que utiliza procesos de selección, análisis de la información y sobre todo resultados de encuestas o estudios de campo que ofrecen experiencias con los consumidores. Tanto el desarrollo inicial a través de pretest como el posterior de pos-test muestran excelentes referencias para aplicar en otras campañas del mismo producto o de otro que se mueve en su mismo campo.

Por otra parte, las fuentes de información no son abundantes en el sector de la publicidad, al menos las específicas de esta área. Sin embargo, han de reforzar las tareas informativas en cada uno de los departamentos. El compromiso del responsable de la documentación o del departamento de investigación es tener al día y actualizadas aquellas que son de uso común en cualquier actividad documental, como anuarios, enciclopedias u obras propias del sector de la publicidad, entre ellas periódicos y revistas.

Resulta difícil, en todo caso, precisar las funciones documentales cuando el desarrollo de la publicidad es sobre todo creatividad. Sin embargo, además del ingenio, la chispa, la iluminación, el sentido, hay que contar con una preparación, es decir, reunir todos los datos con los que hay que enfrentarse para conocer el Scire. 11 : 2 (sep.-dic. 2005) 79-98. ISSN 1135-3761. 
producto, la competencia y, especialmente, el consumidor. Aquí sí hay una justificación documental que ha de orientar al creativo, facilitándole informes sobre esos tres sectores.

\section{Notas}

(1) Existen dos trabajos que amplían las formulaciones aquí señaladas. Por un lado el libro de reciente aparición de los profesores Marcos, García y Nuño (2004, cap. 5). También existe un estudio inicial sobre este tema en Marcos (2002), en el que se señalan las funciones documentales de algunas agencias españolas.

\section{Referencias}

American Marketing Association. URL: <http://www.marketingpower.com>. Consultado: 2004-06-26.

González Lobo, M. a Á. (1998). Curso de publicidad. Madrid: Eresma \& Celeste, 1998.

Gran Enciclopedia RIALP. Madrid: Rialp, 1979. 24 vols.

Izquierdo Arroyo, J. M. (1995). La organización documental del conocimiento. Madrid: Tecnidoc, 1995.

Hernández, Mariana. Soy planner. J. Walter Thompson Madrid. // Adlatina.

URL: <http://www.adlatina.com/notas/noticia.php?id_noticia=8836>. Consultado: 2004-05-24.

López Yepes, J.; García Ros; J. (1993). ¿Qué es documentación? Madrid: Síntesis, 1993.

Malalana Ureña, A. (2002). La documentación en publicidad. // Galdón, G. Teoría y práctica de la documentación informativa. Barcelona: Ariel Comunicación, 2002.

Marcos Recio, Juan Carlos (2002). Evolución y desarrollo de la documentación en el campo publicitario: recursos para optimizar una campaña. // Documentación de las Ciencias de la Información. 25 (2002) 235-265.

Marcos Recio, Juan Carlos; García Jiménez, Antonio; Nuño Moral, M. ${ }^{a}$ Victoria (2004). Gestión de la documentación en la Publicidad y en las Relaciones Públicas. Madrid: Síntesis, 2004.

Ogilvy, David (1965). Confesiones de un publicitario. Barcelona: Ediciones de Occidente, 1965.

Sánchez Guzmán, José Ramón (1979). Introducción a la teoría de la publicidad. Madrid: Tecnos, 1979. 